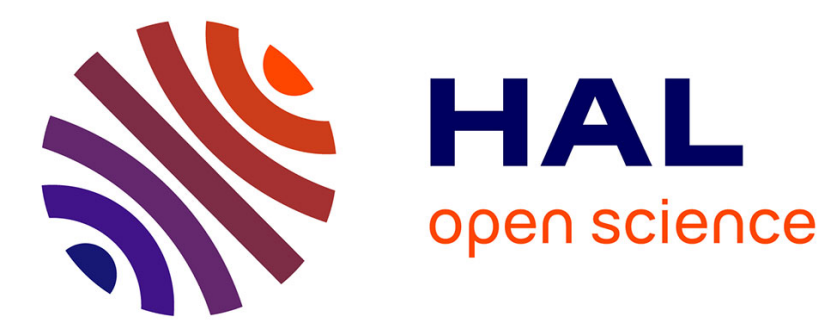

\title{
Overheated metastable states in pulsed laser deposition versus laser radiation wavelength
}

I. Smurov, C. Surry, V. Mazhukin, G. Flamant

\section{To cite this version:}

I. Smurov, C. Surry, V. Mazhukin, G. Flamant. Overheated metastable states in pulsed laser deposition versus laser radiation wavelength. Journal de Physique IV Proceedings, 1994, 04 (C4), pp.C4151-C4-154. 10.1051/.jp4:1994433 . jpa-00252696

\section{HAL Id: jpa-00252696 https://hal.science/jpa-00252696}

Submitted on 1 Jan 1994

HAL is a multi-disciplinary open access archive for the deposit and dissemination of scientific research documents, whether they are published or not. The documents may come from teaching and research institutions in France or abroad, or from public or private research centers.
L'archive ouverte pluridisciplinaire HAL, est destinée au dépôt et à la diffusion de documents scientifiques de niveau recherche, publiés ou non, émanant des établissements d'enseignement et de recherche français ou étrangers, des laboratoires publics ou privés. 


\title{
Overheated metastable states in pulsed laser deposition versus laser radiation wavelength
}

\author{
I. SMUROV, C. SURRY, V.I. MAZHUKIN* and G. FLAMANT ${ }^{* *}$
}

Ecole Nationale d'Ingénieurs de Saint-Etienne, 58 rue Jean Parot, 42023 Saint-Etienne cedex 2, France

${ }^{*}$ Institute of Mathematical Modeling, Russian Academy of Sciences, Miusskaya Square 4,

125047 Moscow, Russia

** Institut de Science et de Génie des Matériaux et Procédés, CNRS, BP. 5, 66125 Font-Romeu cedex,

France

\section{ABSTRACT}

The effect of absorption coefficient of laser radiation on temperature distribution in the material and phase front dynamics is studied by numerical simulation. Overheating of both solid and liquid phases is shown and discussed.

\section{MATHEMATICAL MODEL}

heating, Mathematical description of the processes of laser superconducting ceramics is made within the framework of the combined version of the stefan problem including the dynamics of both phase fronts : melting-solidification and evaporation. The proposed mathematical model is a boundary-value problem for the thermal conductivity equation with two moving phase boundaries solid-liquid $\Gamma_{s 1}(t)$ and liquid-vapour $\Gamma_{1 v}(t)$. Volume heating of the solid and liquid phases is taken into account with the help of the term $\partial G / \partial x$ in the heat transfer (1) and the radiation transfer (2) equations

$$
\begin{aligned}
& {\left[C_{p}(T) e \frac{\partial T}{\partial t}=\frac{\partial}{\partial x} \lambda(T) \frac{\partial T}{\partial x}-\frac{\partial G}{\partial x}\right]_{k}} \\
& {\left[\frac{\partial G}{\partial x}+x G=0\right]_{k}, k=s, 1}
\end{aligned}
$$

solid phase :

$x_{0}<x<\Gamma_{s 1}(t)$,

liquid phase :

$\Gamma_{s 1}(t)<x<\Gamma_{1 v}(t)$,

$t>0$

boundary condition : $\quad \mathbf{x}=\mathbf{x}_{0}, \lambda \frac{\partial \mathrm{T}}{\partial \mathbf{x}}=0$

In the classical version of the stefan problem for the description of melting-solidification phase transitions at the interphase boundary $\Gamma_{s_{1}}(t)$ the differential condition is used

$$
x=\Gamma_{s 1}(t): \quad \lambda_{s} \frac{\partial T_{s}}{\partial x}-\lambda_{1} \frac{\partial T_{1}}{\partial x}=e_{s} L_{m} v_{s 1}
$$




$$
\mathbf{T}_{\mathrm{s}_{1}}=\mathbf{T}_{\mathrm{s}}=\mathbf{T}_{1}=\mathbf{T}_{\mathbf{m}}
$$

from which the velocity of the front movement $u_{s i}$ is determined.

Intensive evaporation gives rise to a strongly nonequilibrium Knudsen layer at the interface. In the present paper the relations reported in [1] are used. In case of volume heating of a condensed medium the boundary conditions on the surface being evaporated have the form :

$$
\begin{aligned}
& x=\Gamma_{1 v}: \quad-\lambda_{s x} \frac{\partial T_{s x}}{\partial x}=\varrho_{s x} L_{v} v_{1 v}+\varepsilon \sigma T_{s x}{ }_{s} \\
& e_{s \times} u_{1 v}=e_{v}\left(u_{1 v}-u\right) \text {, } \\
& P_{S I}+e_{S_{Y} v_{1 v}^{2}}=P_{v}+e_{v}\left(v_{1 v}-u\right)^{2} \text {, } \\
& \left.T_{v}=T_{s} r\left[1+f^{2}\left[\frac{\gamma-1}{\gamma+1}\right] M^{2}\right]^{1 / 2}-f\left[\frac{y-1}{y+1}\right] M\right]^{2} \text {, } \\
& e_{v}=\frac{1}{2} e_{H}\left[\left[\frac{T_{S x}}{T_{v}}\right]^{1 / 2}\left[\left(\gamma M^{2}+1\right) \exp \left(b^{2} M^{2}\right) \operatorname{erfc}(b M)-\frac{4 f}{\pi} M\right]+\right. \\
& +\frac{T_{s x}}{T_{v}}\left[1-2 . f \cdot M \exp \left(b^{2} M^{2}\right) \operatorname{erfc}(b M)\right] \text {, } \\
& M=u / u_{c}, u_{c}=\left(\gamma R T_{v}\right)^{1 / 2}, b=(\gamma / 2)^{1 / 2}, f=(\pi \cdot \gamma / 8)^{1 / 2}, \\
& e_{H}=P_{H} T_{S r} /\left(R T_{s r}\right), P_{H}=p_{b} \exp \left[\frac{L_{v}}{R T_{S r}}\left[1-\frac{T_{b}}{T_{S r}}\right]\right] \\
& G_{s x}=A\left(T_{s x}\right) G_{0} \exp \left[-\left[\frac{t}{\tau}\right]^{2}\right]
\end{aligned}
$$

Nomenclature : a - thermal diffusivity; $A\left(T_{S_{x}}\right)$ - surface absorptivity; $C_{p}$ - heat capacity; $G$ - energy density flux; $G_{0}$ - maximum value of incident energy density flux; $L_{m}$ - latent heat of melting; $\mathrm{L}_{\mathrm{v}}$ - latent heat of evaporation; $M$ - Mach number; $\mathbf{P}$ - pressure; $\mathbf{R}$ - universal gas constant; $\mathbf{T}_{0}$ - initial temperature; $T_{m}$ - melting point; $u$ - vapor velocity; $v_{s_{1}}$ velocity of solid - liquid interface; $v_{1 v}$ - velocity of liquidvapor interface; $V$ - the ratio of heat capacities; $\Gamma_{s_{1}}$ - solidliquid interface; $\Gamma_{1 v}$ - liquid-vapor interface; $x$ - coefficient of heat conductivity; e - density.

$$
\text { Subscripts : b - boiling point; H - saturated vapor; }
$$
1 - liquid phase; s - condensed phase; v - gas phase; sr surface. 


\section{Results and Discussion}

According to the $x(\lambda v)$ curve based on experimental data [2], the absorption coefficient $x$ ranges from $x=8.10^{5} \mathrm{~cm}^{-1}$ for the radiation wavelength $\lambda v=0.2 \mu \mathrm{m}$ to $x=10^{4}$ for the radiation wavelength $\lambda v 21 \mu \mathrm{m}$. Thus, depending on the incident radiation wavelength $\lambda v$, superconducting ceramics can absorb either practically as metals (surface heating) or as dielectrics (volume mechanism of energy release).

The temporal profile of laser pulse was assumed to have the Gaussian shape with respect to the variable $t: G(t)=$ $G_{0} \exp \left(-(t / \tau)^{2}\right)$ where - $c_{t<+\infty,} \tau$ is the pulse half-width at the half-height, $\tau=40 \mathrm{~ns}, G_{0}=10^{7} \mathrm{~W} / \mathrm{cm}^{2}$. In the present simulation $G_{0}$ and $\tau$ remain the same for all the variations of absorption lenght.

Under the combined action of the processes of melting and volume heating, the temperature maximum, Fig.1, is formed in subsurface layers of the material. The presence of the subsurface temperature maximum indicates that a certain volume of the solid phase is overheated with respect to the melting equilibrium temperature $T_{\mathrm{m}}$. Liquid phase heating causes an intensive surface evaporation, which in turn (with allowance for volume energy release in the depth of the liquid phase) leads to the formation of the second temperature maximum. When a certain relation between the parameters is respected, both maxima can be observed simultaneously, Fig. 2.

To show general tendencies of the dynamics of phase transitions, laser action over a wide range of mean free path Iv $\sim x^{-1}$ (from $l v=0$ to $I v=5.10^{3} \mathrm{~A}$ ) was analysed $(\mathrm{Fig} \cdot 3,4$ ). In experiments an explosive decay of the metastable state in solid /liquid phase may lead to an ejection of particles/droplets.

\section{CONCLUSION}

The numerical simulation shows that pulsed energy evaporation of materials with a volume energy release may lead to volume overheating of the solid and liquid phases. The maximum values of the overheating of the solid phase may exceed a hundred degrees and those for the liquid phase may exceed several hundreds degrees. The times of the metastable states existence are tens and hundreds nanoseconds, respectively. Volume energy release leads to the domination of the melting process which, together with a decreased effect of evaporation and low solidification rates, makes the liquid phase lifetime 5-6 times longer than for the surface absorption of radiation. It is shown that the probability of explosive decay of the metastable states in solid phase increaces with laser wavelength, while for the ones in the liquid phase the corresponding dependencies have the maxima versus laser wavelength.

\section{REFERENCES}

1. C.J. Knigt, 1979, AIAA Journal, v.17, pp. 518-523.

2. E. Fogarassy, C. Fuchs, S. de Unamuno, J. Perriere, F. Kerherve; 1992, Materials and Manufacturing Processes, Vol. 7, pp. 3I-51. 

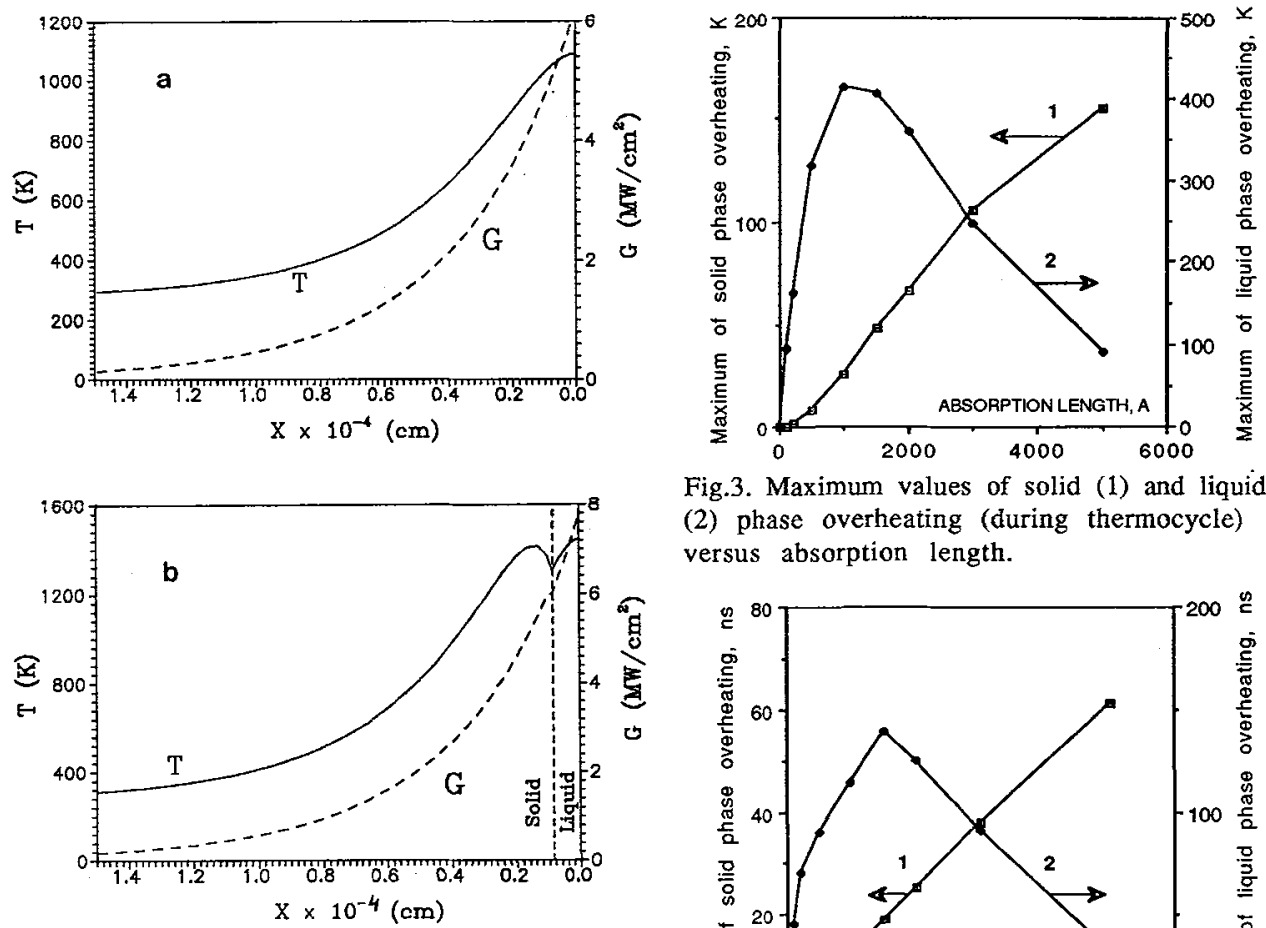

Fig.3. Maximum values of solid (1) and liquid (2) phase overheating (during thermocycle) versus absorption length.

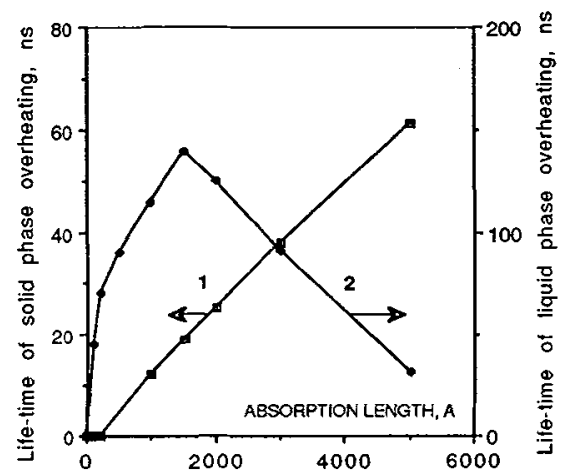

Fig.4. Life-time of solid (1) and liquid (2) phase overheating (during thermocycle) versus absorption length.
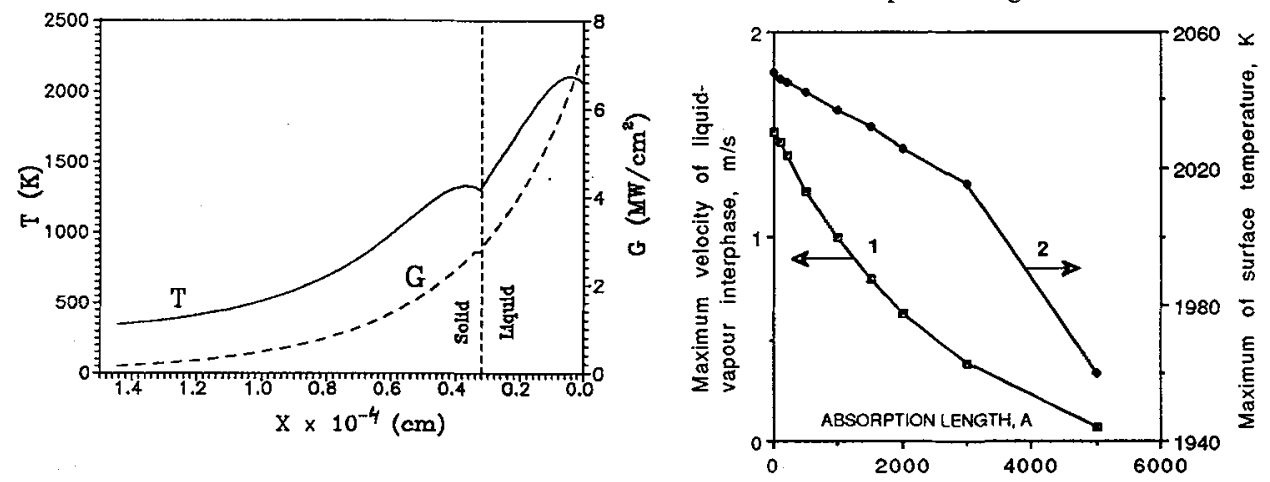

Fig.2. Spatial distribution of temperature $T$ and absorbed energy intensity $G$ illustrating the existance of two subsurface temperature maxima, short time after the Fig. 5. Maximum values of surface temperature (1) and evaporation front velocity (2) during thermocycle versus absorption length. intensive evaporation starts $\left(l_{v}=3000 \mathrm{~A}\right)$. 